\title{
Novel Agents for the Treatment of Multiple Myeloma: Proteasome Inhibitors and
} Immunomodulatory Agents

SANDRA E. KURTIN, RN, MS, AOCN ${ }^{\circledR}$, ANP-C, AND ELIZABETH BILOTTI, MSN, RN, APN, OCN ${ }^{\circledR}$

From University of Arizona Cancer Center, Tucson, Arizona, and John Theurer Cancer Center at Hackensack University Medical Center, Hackensack, New Jersey

Authors' disclosures of potential conflicts of interest are found at the end of this article.

Correspondence to: Sandra E. Kurtin, RN, MS, AOCN, ANP-C, University of Arizona Cancer Center, 6950 North Chapparal Place, Tucson, AZ 85718. E-mail: sandra.kurtin@uahealth.com

(c) 2013 Harborside Press ${ }^{\circledast}$

\section{Abstract}

The integration of novel agents into the treatment of multiple myeloma (MM) has shifted the focus from an incurable disease to one that is chronic, with a realistic hope of someday achieving a cure. Proteasome inhibitors and immunomodulatory agents are the backbone of novel therapies for MM. These agents are particularly important for patients with relapsed or refractory disease, a fate faced by the majority of myeloma patients over the course of their disease. Review of recent clinical trial data for the proteasome inhibitors and immunomodulatory agents, including clinical efficacy and safety information, will assist the advanced practitioner in oncology with integrating these data into the current treatment guidelines for MM.

J Adv Pract Oncol 2013;4:307-321

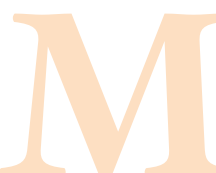

ultiple myeloma (MM) accounts for only $1 \%$ of all malignancies but is the second most common hematologic malignancy, with approximately 21,700 cases diagnosed each year and approximately 10,710 deaths expected in the United States in 2013 (American Cancer Society, 2013). The average age at diagnosis is 69 years. Although MM is not curable, the median overall survival has improved dramatically over the past decade as a result of clinical trials utilizing novel agents in the treatment of all stages of MM. These trials have improved the understanding of the pathobiology of MM and have helped to identify attributes of the malignant clone and the tumor microenvironment, which may provide new therapeutic targets (Palumbo \& Anderson, 2011). Achievement of an early and deep response followed by a sustained response with an acceptable level of toxicity is considered to be the best outcome for treatment of MM and is associated with improved long-term survival (Palumbo \& Cavallo, 2012). 
Proteasome inhibitors and immunomodulatory agents, which are among the novel agents thought to explain the improvement in clinical outcomes for patients with MM, will be the focus of this article. It is important to note that the clinical trial endpoints for the studies discussed vary based on individual trial design and should interpreted within that context. The National Comprehensive Cancer Network (NCCN, 2013) provides guidelines based on analysis of current scientific data by a panel of experts within its membership organizations. Additional treatment guidelines have been suggested by consensus groups such as the International Myeloma Foundation and the Multiple Myeloma Research Foundation. Familiarity with risk-adapted treatment selection, desired clinical outcomes, and the current role of novel agents in the treatment of MM is necessary to effectively incorporate these agents into the treatment paradigm for MM (Tables 1 through 4). Familiarity with the safety and clinical efficacy profile, clinical management guidelines, and patient and caregiver education specific to proteasome inhibitors and immunomodulatory agents will provide the necessary tools for effectively integrating these agents into the treatment plan for patients living with MM.

\section{PROTEASOME INHIBITORS}

The proteasome is an intracellular protein complex responsible for the breakdown of regulatory proteins within the cell, including those that regulate cell-cycle progression, apoptosis, and DNA repair (Adams, 2004); see Figure. The proteolytic cleavage of ubiquitinated proteins within the proteasome core can occur at one or more of three identified subunits: $\beta 1$ (caspase-like activity), $\beta 2$ (trypsinlike activity), and $\beta 5$ (chymotrypsin-like activity); see Table 5. Ultimately, the inhibition of proteasome activity leads to growth arrest and apoptosis, which is particularly important in cancer cells, as they often have a higher level of proteasome activity with an increase in sensitivity to the inhibitory effects when compared with normal cells (Adams, 2004).

\section{Bortezomib}

Bortezomib (Velcade) is a first-in-class reversible proteasome inhibitor that originally received accelerated review by the US Food and Drug Administration (FDA) based on the results of the phase II SUMMIT trial establishing safety and efficacy of single-agent bortezomib vs. pulse dexamethasone in patients with relapsed MM who had received one to three prior lines of therapy (Richardson et al., 2003). The initial findings showed a significant improvement in time to disease progression, with improvements in overall response rate (ORR) and survival (Richardson et al., 2003). Subsequent and final analyses at 22 months of follow-up showed a 6-month improvement in overall survival (OS; 30 vs. 24 months), significant improvement in ORR (43\% vs. 18\%),

\section{Table 1. NCCN-Recommended Treatment of Newly Diagnosed Transplant-Eligible Multiple Myeloma Patients Based on Selected Clinical Trialsa}

\begin{tabular}{|c|c|c|c|c|}
\hline \multirow[b]{2}{*}{ Regimen } & \multirow[b]{2}{*}{$\begin{array}{l}\text { NCCN level } \\
\text { of evidence }\end{array}$} & \multicolumn{3}{|c|}{ Selected clinical trial data } \\
\hline & & $\geq$ VGPR & ORR & $\begin{array}{l}\text { Stem cell } \\
\text { harvest }\end{array}$ \\
\hline Bortezomib/dexamethasone (VD) & 1 & $50 \%$ & $83 \%$ & $96 \%$ \\
\hline Bortezomib/doxorubicin/dexamethasone (BDD) & 1 & $42 \%$ & $83 \%$ & $100 \%$ \\
\hline Bortezomib/thalidomide/dexamethasone (VTD) & 1 & $62 \%$ & $93 \%$ & NR \\
\hline Lenalidomide/low-dose dexamethasone (Rd) & 1 & $40 \%$ & $74 \%$ & $99 \%$ \\
\hline Cyclophosphamide/bortezomib/dexamethasone (CyBorD) & $2 \mathrm{~A}$ & $63 \%$ & $75 \%$ & NR \\
\hline Lenalidomide/bortezomib/dexamethasone (RVD) & $2 \mathrm{~A}$ & $74 \%$ & $100 \%$ & $91 \%$ \\
\hline Dexamethasone & 2B & & & \\
\hline Liposomal doxorubicin/vincristine/dexamethasone & 2B & & & \\
\hline Thalidomide/dexamethasone & 2B & $28 \%$ & $79 \%$ & $90 \%$ \\
\hline
\end{tabular}




\begin{tabular}{|c|c|c|c|c|}
\hline \multirow[b]{2}{*}{ Regimen } & \multirow{2}{*}{$\begin{array}{l}\text { NCCN } \\
\text { level of } \\
\text { evidence }\end{array}$} & \multicolumn{3}{|c|}{ Selected clinical trial data } \\
\hline & & CR & ORR & Survival \\
\hline Lenalidomide/low-dose dexamethasone (Rd) & 1 & $22 \%$ & $89 \%$ & $\begin{array}{l}\text { NYR } \\
1 \mathrm{yr}=99 \% \\
2 \mathrm{yr}=93 \%\end{array}$ \\
\hline Melphalan/prednisone/thalidomide (MPT) & 1 & $27.9 \%$ & $76 \%$ & $47 \mathrm{mo}$ \\
\hline Melphalan/prednisone/thalidomide (MPT), age > 75 & 1 & $7 \%$ & $62 \%$ & $44 \mathrm{mo}$ \\
\hline Melphalan/prednisone/lenalidomide (MPR) & 1 & $24 \%$ & & $1 \mathrm{yr}=100 \%$ \\
\hline Melphalan/prednisone/bortezomib (MPB) & 1 & $30 \%$ & $71 \%$ & $\begin{array}{l}\text { NYR } \\
3-y r \text { OS }=68.5 \%\end{array}$ \\
\hline Bortezomib/dexamethasone & $2 \mathrm{~A}$ & NR & $73 \%$ & NR \\
\hline Melphalan/prednisone (MP) & $2 \mathrm{~A}$ & $4 \%$ & $48 \%$ & $48 \mathrm{mo}$ \\
\hline Dexamethasone (Dex) & 2B & & & \\
\hline Lenalidomide/bortezomib/dexamethasone (RVD) & 2B & $74 \%$ & $100 \%$ & NYR \\
\hline Liposomal doxorubicin/vincristine/dexamethasone (DVD) & 2B & & & \\
\hline Thalidomide/dexamethasone (TD) & 2B & $4 \%$ & $63 \%$ & $42 \mathrm{mo}$ \\
\hline Vincristine/doxorubicin/dexamethasone (VAD) & 2B & & & \\
\hline
\end{tabular}

improved depth of response (complete response [CR] rate of $9 \%$ vs. < 1\%), and a $2.7-$ month improvement in time to disease progression (TTP; Richardson et al., 2007).

San Miguel and colleagues reported data from the randomized phase III VISTA trial evaluating bortezomib in combination with oral melphalan and prednisone (VMP) vs. oral melphalan and prednisone (MP) in non-transplant-eligible newly diagnosed MM patients (San Miguel et al., 2012). At a median follow-up of 60.1 months, there was a $31 \%$ reduced risk of death with VMP vs. MP (hazard ratio [HR], 0.695; $p=.001$; median OS, 56.4 vs. 43.1 months). Time to next therapy (median, 30.7 vs. 20.5 months; HR, 0.557; $p=.001$ ) was longer with VMP than with MP. The analysis also found that this benefit extended to elderly patients ( $\geq 75$ years), those with International Staging System (ISS) stage III disease, and those with renal impairment (creatinine clearance $[\mathrm{CrCl}]<60 \mathrm{~mL} / \mathrm{min}$; San Miguel et al., 2012).

Moreau and colleagues (2011) reported results of a noninferiority study comparing the efficacy of bortezomib as an intravenous (IV) push with a subcutaneous (SC) injection administered with the

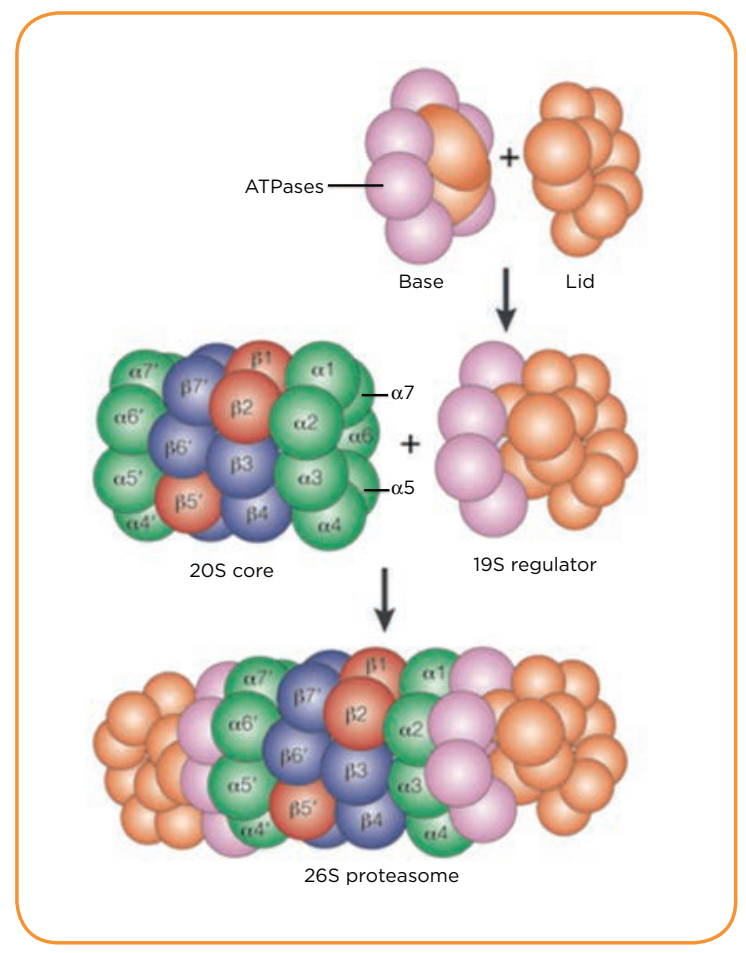

Figure. 26S proteasome structure. Adapted with permission from Kloetzel (2001). 


\section{Table 3. NCCN-Recommended Maintenance Therapy Following Stem Cell Transplant or Continuous Treatment in Transplant-Ineligible Patients With Multiple Myeloma ${ }^{a}$

\begin{tabular}{|c|c|c|}
\hline Agent & $\begin{array}{l}\text { NCCN level } \\
\text { of evidence }\end{array}$ & Rationale for NCCN recommendation \\
\hline Lenalidomide & 1 & $\begin{array}{l}\text { Based on improvement in PFS following HCT } \\
\text { Based on improvement in PFS following initial treatment with MPR in transplant- } \\
\text { ineligible patients }\end{array}$ \\
\hline Thalidomide & 1 & Based on improvement in EFS and OS \\
\hline Bortezomib & $2 \mathrm{~A}$ & Based on improvement in response rates \\
\hline
\end{tabular}

same dose and schedule in bortezomib-naive relapsed MM patients who had received one to three prior therapies (Moreau et al., 2011). There were no differences in ORR, depth of response, or time to response between the two study arms; however, the incidence of peripheral neuropathy (PN) was significantly reduced in the cohort treated with SC bortezomib (38\% vs. $53 \%$ all grades, $6 \%$ vs. $16 \%$ grade 3 and higher; Moreau et al., 2011). The results of this trial have led to a change in the favored route of administration from IV to SC and a change in the standard schedule of administration to a twice-

\footnotetext{
Table 4. Current FDA-Approved Options for Salvage Treatment in Patients With Relapsed or Refractory Multiple Myeloma Based on Selected Clinical Trialsa

\section{Regimen}

Proteasome inhibitor-containing regimens

Bortezomib Bortezomib (category 1)

Bortezomib/liposomal doxorubicin (category 1)

Lenalidomide/bortezomib/dexamethasone (RVD) (category 1)

Bortezomib/dexamethasone

Cyclophosphamide/bortezomib/dexamethasone

Dexamethasone, thalidomide, cisplatin, doxorubicin, cyclophosphamide, etoposide, and bortezomib (VTD-PACE)

Carfilzomib Indicated as a single agent for patients with MM who have received 2 prior therapies including bortezomib and an immunomodulatory agent and have demonstrated disease progression on or within 60 days of completion of the last therapy

Immunomodulatory agent-containing regimens

Lenalidomide Lenalidomide/bortezomib/dexamethasone (category 1)

Lenalidomide/low-dose dexamethasone (Rd)

Pomalidomide Indicated for patients with MM who have received at least 2 prior therapies including lenalidomide and bortezomib and have demonstrated disease progression on or within 60 days of completion of the last therapy

Thalidomide

Thalidomide/dexamethasone

Other regimens

Dexamethasone, cyclophosphamide, etoposide, and cisplatin (DCEP)

Dexamethasone, thalidomide, cisplatin, doxorubicin, cyclophosphamide, and etoposide (DT-PACE)

Note. FDA = US Food and Drug Administration; MM = multiple myeloma. Information from NCCN (2013), Onyx Pharmaceuticals (2012), Celgene (2013), Millennium (2012).

aGoal: Establish disease control with acceptable toxicity and improved or acceptable quality of life. Care should be used in selecting agents based on transplant eligibility and residual toxicities.
} 
weekly dosing schedule for two cycles, followed by weekly dosing. Together, these changes offer similar efficacy, the opportunity to improve treatment outcomes with continued therapy, and improved quality of life by lessening toxicity (Moreau, 2012).

\section{Carfilzomib}

Carfilzomib (Kyprolis) is a second-in-class irreversible proteasome inhibitor approved for the treatment of patients with MM who have received at least two prior therapies including bortezomib and an immunomodulatory agent and have demonstrated relapsed or refractory disease (Onyx Pharmaceuticals, 2012). Relapsed or refractory disease is defined as disease progression on or within 60 days of completion of the last therapy.

The phase II PX-171-003-Al study established safety and efficacy of single-agent carfilzomib in the treatment of patients with relapsed and/or refractory MM ( $\mathrm{n}=257$, median age 63 years; Siegel et al., 2012). The median number of prior lines of therapy was 5 . A total of $74 \%$ of patients had documented disease progression on their most recent line of therapy. All but one patient had received bortezomib, and all patients had received an immunomodulatory agent. A total of $73 \%$ of the patients were refractory to bortezomib; $80 \%$ were refractory or intolerant (therapy discontinued due to toxicity) to both bortezomib and lenalidomide.

The ORR in the heavily pretreated population was $23.7 \%$ (61/257) for the response-evaluable patients, with a median duration of response of 7.8 months (Siegel et al., 2012); see Table 6. Patients meeting the eligibility criteria for this trial are similar to those analyzed by Kumar et al. (2012b), where patients who were identified as refractory to bortezomib and either refractory to, intolerant to, or ineligible for immunomodulatory therapy had an expected OS of 9 months once identified (Kumar et al., 2012b). The efficacy results of the single-agent carfilzomib trial are promising in this patient population.

Pooled data from 526 patients with MM enrolled in four phase II single-agent carfilzomib trials (PX171-003-A0, PX-171-003-A1, PX-171-004, and PX-171$005)$ were analyzed for various safety endpoints. The first analysis focused on the hematologic toxicities, both overall and grade $3 / 4$. It was found that the thrombocytopenia was cyclical, similar to bortezomib, with the nadir on day 8 of the treatment cycle (Nooka et al., 2012). No clinically significant bleed- ing episodes ( $<1 \%$ grade 3 and no grade 4$)$ were associated with concurrent thrombocytopenia. Only a $1 \%$ incidence of febrile neutropenia was reported, despite a reported grade $3 / 4$ neutropenia incidence of $12 \%$. Anemia was reported at $46.8 \%$ for all grades, with $22.4 \%$ grade $3 / 4$ (Nooka et al., 2012).

The second analysis focused on renal complications, as this is a common concern when treating patients with MM. Moderate to severe renal dysfunction $(\mathrm{CrCl}<50 \mathrm{~mL} / \mathrm{min})$ was reported in $23.8 \%$ of patients at the time of study entry (Harvey et al., 2012). Worsening renal function was transient in $6 \%$ of patients (average duration 1.4 weeks) and sustained in $7 \%$ of patients; however, only $1.5 \%$ of patients required treatment discontinuation due to renal dysfunction (Harvey et al., 2012). As the PX-171-005 data reported no difference in the pharmacokinetics, safety, or efficacy when carfilzomib was used in patients with varying degrees of renal impairment, including those on dialysis, no dose adjustment is indicated (Niesvizky et al., 2011).

The final subset analysis focused on the incidence of either worsening or treatment-emergent $\mathrm{PN}$, which can be a dose-limiting toxicity of proteasome inhibitor therapy. A history of PN attributed to prior treatment for MM was reported by $84.8 \%$ of patients, with $71.9 \%$ of patients having either grade 1 or $2 \mathrm{PN}$ at the time of study entry (Martin et al., 2012). The reported incidence of PN in all carfilzomib studies was $13.9 \%$ overall, with $12.5 \%$ grades $1 / 2,1.3 \%$ grade 3 , and no grade 4 . Dose adjustment $(0.8 \%, \mathrm{n}=4)$ or discontinuation of carfilzomib $(0.2 \%, \mathrm{n}=1)$ due to $\mathrm{PN}$ was rare (Martin et al., 2012).

Carfilzomib continues to be studied in multiple settings. The current dosing recommendations suggest a body surface area limit of $2.2 \mathrm{~m}^{2}$. Many study designs are evaluating its use in combination with other antimyeloma therapies in both the newly diagnosed and relapsed settings. It is also being evaluated in dose-escalation studies to determine the maximum tolerated dose (MTD) in both solid tumors and hematologic malignancies, including MM.

\section{Proteasome Inhibitors Under Investigation}

Although there are numerous new proteasome inhibitors in the pipeline for both multiple myeloma and other malignancies, there are safety and efficacy data available in a small number of patients from both phase I and II trials for two of these agents. 


\section{Table 5. Mechanism of Action, Dosing, and Route of Administration of Proteasome Inhibitors}

\begin{tabular}{|c|c|c|c|c|}
\hline Agent & Class & Type of inhibition & Dose & $\begin{array}{l}\text { Route of } \\
\text { administration }\end{array}$ \\
\hline Bortezomib & $\begin{array}{l}\text { Boronate } \\
\beta 5, \beta 1\end{array}$ & Reversible & $1.3 \mathrm{mg} / \mathrm{m}^{2}$ days $1,4,8,11$ q21 days & IV and SC \\
\hline Carfilzomib & $\begin{array}{l}\text { Epoxyketone } \\
\beta 5\end{array}$ & Irreversible & $\begin{array}{l}20 \mathrm{mg} / \mathrm{m}^{2} \text { days } 1,2,8,9,15,16 \text { for } \\
\text { cycle } 1 \text {, then } 27 \mathrm{mg} / \mathrm{m}^{2} \text { days } 1,2,8,9 \text {, } \\
15,16 \mathrm{q} 28 \mathrm{~d} \text { for subsequent cycles }\end{array}$ & IV \\
\hline $\begin{array}{l}\text { Marizomib } \\
(\mathrm{NPI}-0052)\end{array}$ & $\begin{array}{l}\beta \text {-lactone } \\
\beta 5, \beta 2\end{array}$ & Irreversible & $\begin{array}{l}\text { MTD: } 0.4 \mathrm{mg} / \mathrm{m}^{2} \text { over } 60 \mathrm{~min} \text { or } \\
0.5 \mathrm{mg} / \mathrm{m}^{2} \text { over } 120 \mathrm{~min}\end{array}$ & IV \\
\hline $\begin{array}{l}\text { Ixazomib } \\
\text { (MLN9708) }\end{array}$ & $\begin{array}{l}\text { Boronate } \\
\beta 5\end{array}$ & Reversible & $\begin{array}{l}\text { Variable depending on dosing } \\
\text { schedule and combination }\end{array}$ & Oral \\
\hline $\begin{array}{l}\text { Oprozomib } \\
\text { (ONX-0912) }\end{array}$ & $\begin{array}{l}\text { Epoxyketone } \\
\beta 5\end{array}$ & Irreversible & $\begin{array}{l}\text { Variable depending on dosing } \\
\text { schedule }\end{array}$ & Oral \\
\hline
\end{tabular}

\section{Table 6. Key Clinical Trials for Approval of Proteasome Inhibitors}

\begin{tabular}{|c|c|c|c|}
\hline Trial & Resulting indication & Clinical trial dosing/design & Efficacy \\
\hline APEXa & $\begin{array}{l}\text { Relapsed MM after receiving } 1 \text { prior } \\
\text { line of therapy }\end{array}$ & $\begin{array}{l}\text { Bortezomib } 1.3 \mathrm{mg} / \mathrm{m}^{2} \text { IV days } 1,4,8,11 \\
\text { q21d ( } 8 \text { cycles) then } \\
\text { Bortezomib } 1.3 \mathrm{mg} / \mathrm{m}^{2} \text { days } 1,8,15,22 \\
\text { every q35d ( } 3 \mathrm{cycles} \text { ) } \\
\text { VS. } \\
\text { Dexamethasone } 40 \mathrm{mg} \text { po days } 1-4,9-12 \text {, } \\
17-20 \text { q35d ( } 4 \text { cycles) then } \\
\text { Dexamethasone } 40 \mathrm{mg} \text { po days } 1-4 \mathrm{q} 28 \mathrm{~d} \\
\text { (4 cycles) }\end{array}$ & $\begin{array}{l}\text { ORR: } 43 \% \\
\text { PR: } 34 \% \\
\text { CR: } 9 \% \\
\text { OS: } 29.8 \text { mo } \\
\text { ORR: } 18 \% \\
\text { PR: } 17 \% \\
\text { CR: }<1 \% \\
\text { OS: } 23.7 \text { mo }\end{array}$ \\
\hline VISTA $^{b}$ & Treatment of patients with MM & $\begin{array}{l}\text { Bortezomib } 1.3 \mathrm{mg} / \mathrm{m}^{2} \text { IV days } 1,4,8,11 \\
22,25,29,32 \\
\text { Melphalan } 9 \mathrm{mg} / \mathrm{m}^{2} \text { po days } 1-4 \\
\text { Prednisone } 60 \mathrm{mg} / \mathrm{m}^{2} \text { po days } 1-4 \mathrm{q} 6 \mathrm{wk} \\
\text { ( } 4 \text { cycles }=24 \mathrm{wk} \text { ) then } \\
\text { Bortezomib } 1.3 \mathrm{mg} / \mathrm{m}^{2} \text { IV days } 1,8,22,29 \\
\text { Melphalan: no change } \\
\text { Prednisone: no change } \\
\text { q6wk ( } 5 \text { cycles }=30 \mathrm{wk} \text { ) } \\
\text { VS. } \\
\text { Melphalan } 9 \mathrm{mg} / \mathrm{m}^{2} \text { po days } 1-4 \\
\text { Prednisone } 60 \mathrm{mg} / \mathrm{m}^{2} \text { po days } 14 \\
\text { q6wk ( } 9 \text { cycles }=54 \mathrm{wk} \text { ) }\end{array}$ & $\begin{array}{l}\text { ORR: } 71 \% \\
\text { CR: } 30 \% \\
\text { TTP: } 24 \mathrm{mo} \\
\text { OS: } 56.4 \mathrm{mo} \\
\text { ORR: } 35 \% \\
\text { CR: } 4 \% \\
\text { TTP: } 16.6 \mathrm{mo} \\
\text { OS: } 43.1 \mathrm{mo}\end{array}$ \\
\hline $\begin{array}{l}\text { PX-171- } \\
\text { OO3-A } 1^{C}\end{array}$ & $\begin{array}{l}\text { Treatment of patients with MM } \\
\text { who have received at least } 2 \text { prior } \\
\text { therapies including bortezomib } \\
\text { and an immunomodulatory agent } \\
\text { and have demonstrated disease } \\
\text { progression on or within } 60 \text { days } \\
\text { of completion of the last therapy. } \\
\text { Approval is based on response rate. } \\
\text { Clinical benefit, such as improvement } \\
\text { in survival or symptoms, has not been } \\
\text { verified. }\end{array}$ & $\begin{array}{l}\text { Carfilzomib } 20 \mathrm{mg} / \mathrm{m}^{2} \text { (cycle } 1 \text { ), } 27 \mathrm{mg} / \mathrm{m}^{2} \\
\text { (cycles } 2-12 \text { ) IV over 2-10 min days 1, } 2 \text {, } \\
8,9,15,16 \mathrm{q} 28 \mathrm{~d}\end{array}$ & $\begin{array}{l}\text { ORR: } 22.9 \% \\
\text { DOR: } 7.8 \mathrm{mo} \\
\text { OS: } 15.6 \mathrm{mo}\end{array}$ \\
\hline
\end{tabular}


Marizomib (NPI-0052) is an irreversible proteasome inhibitor administered intravenously. At present, two phase I dose-escalation trials have evaluated safety outcomes in patients with relapsed and refractory MM. Most of the patients enrolled had prior bortezomib exposure, with $71 \%$ documented as bortezomib refractory with a median of 6 prior lines of therapy. An ORR of 14\% (all partial responses) was reported, with stable disease or better in 73\% (Richardson et al., 2011a). The dose-limiting toxicities in those trials were reversible neurologic symptoms, including transient hallucinations, cognitive changes, and loss of balance. This agent continues to be evaluated on a twice-weekly schedule at a dose of $0.5 \mathrm{mg} / \mathrm{m}^{2}$ IV over 120 minutes on days $1,4,8$, and 11 of a 21day cycle either alone or with low-dose oral dexamethasone $20 \mathrm{mg}$ the day prior to and day of marizomib dosing (Richardson et al., 2011a).

Ixazomib (MLN9708) is an orally administered reversible proteasome inhibitor currently investigated in phase I studies evaluating both weekly and biweekly dosing schedules in relapsed/refractory MM patients. Lonial et al. (2012) reported data from the twice-weekly dosing schedule with ixazomib on days $1,4,8$, and 11 of a 21-day cycle. The identified MTD was $2 \mathrm{mg} / \mathrm{m}^{2}$ (Lonial et al., 2012). Adverse events (AEs) were common ( $91 \%$ of patients reporting at least one $\mathrm{AE}$ ), with the most frequently reported treatment-emergent adverse events (TEAEs) being thrombocytopenia, neutropenia, fatigue, nausea, diarrhea, and rash. Peripheral neuropathy was mild (10\% overall, no grade 3 or greater reported).

Among the 53 evaluable patients, responses were 1 near CR (nCR), 1 very good partial response (VGPR), 3 partial responses (PRs), and 1 stringent $\mathrm{CR}$ (sCR) occurring in a bortezomib-naive patient (Lonial et al., 2012). At the same time, Kumar et al. (2012a) reported results from the once-weekly dosing schedule of ixazomib on days 1,8 , and 15 of a 28-day cycle. In this patient population, three dose-limiting toxicities (DLTs) were seen, including one grade 3 rash and two grade 3 GI adverse events, with a MTD of $2.97 \mathrm{mg} / \mathrm{m}^{2}$ orally. Treatment response in the 18 evaluable patients included 1 VGPR, 1 PR, and 8 patients with stable disease lasting up to 9.5 months (Kumar et al., 2012a).

A phase I/II study evaluating twice-weekly oral ixazomib in combination with lenalidomide and dexamethasone (oral ixazomib $4 \mathrm{mg}$ on days
1,8 , and 15 with oral lenalidomide $25 \mathrm{mg}$ on days 1 through 21 and oral dexamethasone $40 \mathrm{mg}$ on days $1,8,15$, and 22 of a 28 -day cycle) in newly diagnosed MM patients reported preliminary results (Richardson et al., 2012). Of 64 evaluable patients, combined responses for phase I/II revealed an ORR of $91 \%$, with $39 \%$ VGPR or better (Richardson et al., 2012). The most commonly reported TEAEs ( $\geq$ grade 3 ) included vomiting, nausea, thrombocytopenia, syncope, lymphopenia, and fatigue. Peripheral neuropathy occurred in $21 \%$ of patients, with $>$ grade 3 reported in one patient treated with a dose of ixazomib above the MTD. These trials offer the promise of additional proteasome inhibitors for the management of patients with multiple myeloma.

\section{IMMUNOMODULATORY AGENTS}

The immunomodulatory agents represent a class of drugs with versatile therapeutic properties, including antiproliferative effects on the malignant clone (antitumor effect), immunomodulatory effects (costimulation of $\mathrm{T}$ cells, suppression of regulatory $\mathrm{T}$ cells [Tregs], and activation of natural killer [NK] cells), and disruption of plasma cell (PC) microenvironment interactions (antiangiogenesis, anti-inflammatory cytokines, downregulation of adhesion molecules, and antiosteoclastogenic properties; Morgan, Walker, \& Davies, 2012, Palumbo \& Anderson, 2011; Quach et al., 2010); see Table 7. The immunomodulatory agents are analogs of thalidomide (Thalomid), first used therapeutically for the treatment of relapsed/refractory MM in the late 1990s. More recently, clinical trials using lenalidomide (Revlimid) and pomalidomide (Pomalyst), both analogs of thalidomide, have shown clinical efficacy with different toxicity profiles compared with those of thalidomide.

Given the pleiotropic mechanism of action, these compounds have been effective in the treatment of MM in combination with dexamethasone as well as in combination with both standard therapies and other novel agents (Quach, Kaiff, \& Spencer, 2012; Stewart, 2012; Rajkumar, 2012). As the number of trials conducted over the past decade incorporating thalidomide and lenalidomide in the treatment of MM exceeds 50, with safety and efficacy profiles well established, the focus of this article will be on key trials that have established the conceptual basis for the use of these two agents 


\section{Table 7. Mechanism of Action of Thalidomide, Lenalidomide, and Pomalidomide}

\begin{tabular}{|c|c|}
\hline Agent & Proposed mechanism of action \\
\hline Thalidomide & $\begin{array}{l}\text { Weak T-cell costimulation (+) } \\
\text { NK and KKT cell activation }(+) \\
\text { Antiangiogenesis (++++) } \\
\text { Anti-inflammatory properties*(+) } \\
\text { Antiproliferative activity }(+) \\
\text { Downregulation of adhesion } \\
\text { molecules } \\
\text { Antiosteoclastogenic properties }\end{array}$ \\
\hline Lenalidomide & $\begin{array}{l}\text { Strong T-cell costimulation }(++++) \\
\text { Tregs suppression }(+) \\
\text { NK and KKT cell activation }(++++) \\
\text { ADCC }(++++) \\
\text { Antiangiogenesis }(+++) \\
\text { Anti-inflammatory properties* } \\
(++++) \\
\text { Antiproliferative activity }(+++) \\
\text { Downregulation of adhesion } \\
\text { molecules } \\
\text { Antiosteoclastogenic properties }\end{array}$ \\
\hline Pomalidomide & $\begin{array}{l}\text { Strongest T-cell costimulation } \\
(+++++) \\
\text { Tregs suppression (+) } \\
\text { NK and KKT cell activation (+++++) } \\
\text { ADCC }(++++) \\
\text { Antiangiogenesis }(+++) \\
\text { Anti-inflammatory properties* } \\
(++++) \\
\text { Antiproliferative activity (+++) } \\
\text { Downregulation of adhesion } \\
\text { molecules } \\
\text { Antiosteoclastogenic properties }\end{array}$ \\
\hline
\end{tabular}

Note. $(+)=$ relative potency factor of 10; Tregs $=$ regulatory $\mathrm{T}$-cell suppression; $\mathrm{NK}=$ natural killer; ADCC = antibody-dependent cellular toxicity. Information from Quach et al. (2010), Sedlarikova et al. (2012), Pan \& Lentzsch (2012).

*Anti-inflammatory properties include TNF $\alpha$ and IL-6 inhibition.

in specific phases of MM (Tables 1 through 4). Pomalidomide is the newest immunomodulatory agent, approved by the FDA in February 2013. All three agents require dispensing using a safety program due to the historic data documenting the teratogenicity of thalidomide when used as a sedative and antiemetic drug to treat morning sickness in the first trimester of gestation (McBride, 1961; Lenz, 1962). No teratogenic events have been reported in clinical trials to date for either lenalidomide or pomalidomide.

\section{Thalidomide}

Thalidomide was first reported to have benefit in MM in 1999 in patients with advanced relapsed disease, opening the door for investigating targeted therapies (Singhal et al., 1999). Since that time, numerous trials using thalidomide as a single agent or in combination with dexamethasone or melphalan and prednisone have continued to show benefit. It is currently recommended for the treatment of newly diagnosed patients with MM in both the transplant-eligible and non-transplant eligible populations as well as in patients with relapsed disease (Tables 1 through 4 ). The chemical structure and clinical experiences of thalidomide were exploited to create the newer immunomodulatory agents lenalidomide and pomalidomide.

\section{Lenalidomide}

Lenalidomide was approved for the treatment of MM in 2006. E4A03, a large Eastern Cooperative Oncology Group (ECOG) phase III study, established the efficacy and safety of lenalidomide plus high-dose (RD) or low-dose (Rd) dexamethasone in newly diagnosed multiple myeloma. The 1- and 2 -year survival rates were $96 \%$ and $87 \%$, respectively, for high-dose dexamethasone vs. $88 \%$ and $75 \%$, respectively, for low-dose dexamethasone, with subsequent 3-year survival rates of $75 \%(\mathrm{RD})$ vs. $74 \%(\mathrm{Rd})$. It is important to note that the incidence of deep-vein thrombosis (DVT) was $12 \%$ vs. $26 \%$ in the Rd and RD arms, respectively. Additionally, the rate of infection in the RD group was higher. These results demonstrated the efficacy and safety of the lenalidomide/ dexamethasone combination for previously untreated patients and also raised important questions about the continued use of high-dose dexamethasone vs. the treatment of newly diagnosed multiple myeloma.

Two important phase III trials evaluated the role of lenalidomide/with high-dose dexamethasone vs. high-dose dexamethasone alone in the relapsed setting: MM-009 and MM010. At 48 months of followup, pooled analysis of these data confirms superior efficacy of the lenalidomide/dexamethasone arm with improved ORR/CR (61\% vs. $15 \% ; p<.001$ ), improved TTP (13.4 vs. 4.6 months), and improved OS (38 vs. 31.6 months; $p=.045$ ). The incidence of thromboembolic events in these trials was $16 \%$, yet prophylactic anticoagulation was not mandatory.

More recent trials have incorporated lenalidomide in combination with other agents such as bortezomib. A phase I/II trial evaluating the combination of lenalidomide, bortezomib, and dexamethasone (RVD) in newly diagnosed MM patients reported response rates of $100 \%$, with $74 \%$ VGPR or better (Rajkumar, 2012). Additional trials have evaluated the role 
of maintenance lenalidomide following autologous stem cell transplantation, showing improvement in event-free survival (EFS); see Tables 1 through 4 .

\section{Pomalidomide}

Pomalidomide, like lenalidomide, is an immunomodulatory compound with pleiotropic properties shown to be beneficial in treating MM. Both agents have been shown to be more potent than thalidomide, with additional immunomodulatory properties thought to enhance the antimyeloma effect, including T-cell costimulation, regulatory T-cell suppression, NK cell activation, and enhanced antibody dependent cell-mediated cytotoxicity (Table 7).

The efficacy of pomalidomide was first established in a small $(n=60)$ group of relapsed MM patients who had received from 1 to 3 prior therapies, including autologous hematopoietic cell transplantation (Schey et al., 2004). Patients in the first cohort received pomalidomide (POM) $2 \mathrm{mg}$ daily $21 / 28$ days, weekly dexamethasone (LoDEX) $40 \mathrm{mg}$, and aspirin $325 \mathrm{mg}$ daily. The MTD of pomalidomide in this population was $2 \mathrm{mg}$, primarily due to myelosuppression, with neutropenia (32\% > grade 3 ) being the most common. Efficacy was established based on a reduction in paraprotein (> 25\% in $67 \%, \geq 50 \%$ in $54 \%, 17 \%$ with CR). It is important to note that patients refractory to other novel agents, including lenalidomide (40\%), thalidomide (37\%), and bortezomib (60\%), responded to POM.

A number of trials followed the initial phase I study (Table 8). The majority of these trials combined POM with weekly DEX. Five phase II stud- ies were conducted in sequence by Lacy and colleagues (2009) with variable dosing of POM. The initial cohort of relapsed/refractory MM patients (similar characteristics) received the same regimen as in the phase I trial. Responses included 5\% CR, 28\% VGPR, and 30\% PR. Additionally, responses in patients refractory to other novel agents were reported in $40 \%$ of lenalidomide-refractory patients, $37 \%$ of thalidomide-refractory patients, and $60 \%$ of bortezomib-refractory patients, confirming the role of POM/LoDEX in patients refractory to those agents (Lacy et al., 2009).

Higher doses of POM in combination with LoDEX in relapsed/refractory MM followed these trials. Lacy and colleagues evaluated three additional cohorts of patients, confirming the efficacy of POM/DEX and concluding that a higher dose of POM (4 mg daily) with DEX did not improve clinical outcomes (Lacy et al., 2011).

Richardson and colleagues (2011b) studied POM (4 mg 21/28)/DEX (40 mg weekly) compared to POM (4 mg 21/28) in a relapsed/refractory MM population $(\mathrm{n}=221$ : POM + LoDEX, $\mathrm{n}=113$; POM, $\mathrm{n}=108)$. The trial did allow a crossover for patients with progressive disease on the POM-alone arm of the trial. A total of 61 (56\%) of these patients went on to receive POM + LoDEX due to progressive disease (PD). Response rates favored the POM/DEX arm of the trial ( $\mathrm{PR}$ of $34 \%$ vs. 13\%), with responses seen in patients refractory to novel agents (lenalidomide $30 \%$ and bortezomib 16\%), suggesting a synergistic effect of the combined regimen. My-

\section{Table 8. Clinical Trials of Pomalidomide}

\begin{tabular}{|c|c|c|c|c|}
\hline Trial/investigator & Phase & Trial design & Population & ORR \\
\hline Lacy et al. (2009) & II & 2 mg/day + low-dose DEX & $\begin{array}{l}\text { Prior THAL or LEN }(62 \%) \\
(n=60)\end{array}$ & $63 \%$ \\
\hline Lacy et al. (2010) & II & 2 mg/day + low-dose DEX & LEN-refractory $(n=34)$ & $32 \%$ \\
\hline $\begin{array}{l}\text { IFM 2009-02 } \\
\text { Leleu et al. (2011) }\end{array}$ & II & 4 mg/day + low-dose DEX & $\begin{array}{l}\text { Relapsed or refractory to } \\
\text { LEN and BTZ }(n=84)\end{array}$ & $35 \%$ \\
\hline Richardson et al. (2011b) & II & 4 mg/day + low-dose DEX & $\begin{array}{l}\text { Majority refractory to LEN } \\
\text { and BTZ }(n=221)\end{array}$ & $34 \%$ \\
\hline CC-4047-MM-007 & III & $\begin{array}{l}\text { POM, BTZ, low-dose DEX vs. } \\
\text { BTZ + low-dose DEX }\end{array}$ & $\begin{array}{l}\text { Relapsed or relapsed/ } \\
\text { refractory MM }\end{array}$ & $\begin{array}{l}\text { Primary endpoint: } \\
\text { Response (IMWG } \\
\text { criteria) }\end{array}$ \\
\hline NCT01632826 & & $\begin{array}{l}\text { Expanded access trial for POM } \\
4 \mathrm{mg} / \text { day + low-dose DEX }\end{array}$ & $\begin{array}{l}\text { Relapsed or relapsed/ } \\
\text { refractory MM }\end{array}$ & \\
\hline
\end{tabular}


elosuppression, in particular grade $>3$ neutropenia $(38 \%-47 \%)$, was the most common reason for treatment discontinuation.

This trial confirmed the superior efficacy of POM in combination with LoDEX vs. POM alone. In February 2013, the FDA granted accelerated approval to pomalidomide (Celgene, 2013) for the treatment of patients with multiple myeloma who have received at least two prior therapies, including lenalidomide and bortezomib, and have demonstrated disease progression on or within 60 days of completion of the last therapy. As a condition of this accelerated approval, the FDA will require submission of the results of clinical trial CC-4047-MM-007, a randomized trial of pomalidomide added to bortezomib and LoDEX compared to bortezomib plus LoDEX in patients with previously treated multiple myeloma. Pomalidomide is now being evaluated in a number of trials to establish optimal dosing and tolerance in combination with other novel agents (Table 8).

\section{TOXICITIES ASSOCIATED WITH PROTEASOME INHIBITORS AND IMMUNOMODULATORY COMPOUNDS}

Although the proteasome inhibitors and immunomodulatory compounds offer excellent efficacy and additional therapeutic options for patients, familiarity with TEAEs is necessary (Tables 9 and 10). Most patients will receive all agents over the course of their disease with some variability in TEAEs based on both patient and disease-related factors. Each class of agents has some unique TEAEs and these may vary within each class. For example, TEAEs vary within the proteasome inhibitor class due to the differences in targets within the proteasome and the chemical structure of these drugs. Similarly, TEAE profiles vary for the immunomodulatory agents due to the potency of each agent and the secondary changes in the malignant clone and the tumor microenvironment. Each patient must be evaluated prior to initiating therapy for existing comorbid conditions, unresolved toxicities, and risk for new or progressive TEAEs with continued treatment. The goals of therapy and the patient's wishes must always be considered. Supportive care is essential throughout the continuum of care to minimize the severity of TEAEs. Management strategies for some of the more common side effects of commercially available proteasome inhibitors and immunomodulatory agents will be discussed.
Myelosuppression is a common finding in patients with MM, with anemia often present at the time of diagnosis, while leukopenia/neutropenia and thrombocytopenia emerge more often during treatment and in the relapsed and refractory settings. Familiarity with the incidence, severity, and duration of cytopenias reported in clinical trials for the proteasome inhibitors and immunomodulatory agents will provide a guide for planning the timing and frequency of monitoring blood counts. Guidelines for dose modifications or treatment are provided in the prescribing information for each drug. Supportive care using blood and platelet transfusions or growth factors may be used to prevent more serious AEs at the discretion of the clinician. Pretreatment blood cell counts will determine the feasibility of same-day treatment.

Each patient will need to be evaluated based on their disease status, goals of treatment, bone marrow capacity, comorbid conditions including medications, and general health (Kurtin, 2012). Educating the patient and caregivers on prevention of infections and bleeding, as well as reportable signs and symptoms will allow for prompt intervention and reduce the severity of adverse events (Table 10). Providing recommendations for patients to conserve energy but remain active will minimize the effects of fatigue associated with the disease, treatment, or underlying anemia.

Peripheral neuropathy is a complex process with multiple potential contributing factors in the patient with MM, including the disease itself, diabetes, endocrine disorders, nutritional diseases, vascular disease, connective tissue disease, medications, postherpetic neuralgia, and other causes (Richardson et al., 2010). The incidence of PN attributed to MM treatment varies by class of drug, by agent and dosing schedule (Table 9). Baseline evaluation of each patient is critical to identify contributing factors that may be reversed, and to implement well-established guidelines for dose modification or discontinuation of agents that are associated with more severe PN. Given the improved trends in survival and the expanded options for treatment, irreversible and debilitating $\mathrm{PN}$ is an unacceptable outcome. Refinement of dosing and scheduling of novel agents for MM has improved the incidence and severity of $\mathrm{PN}$, however, health-care providers must be able to identify patients at increased risk, establish a standard for evaluating the onset or progression of $\mathrm{PN}$; and 


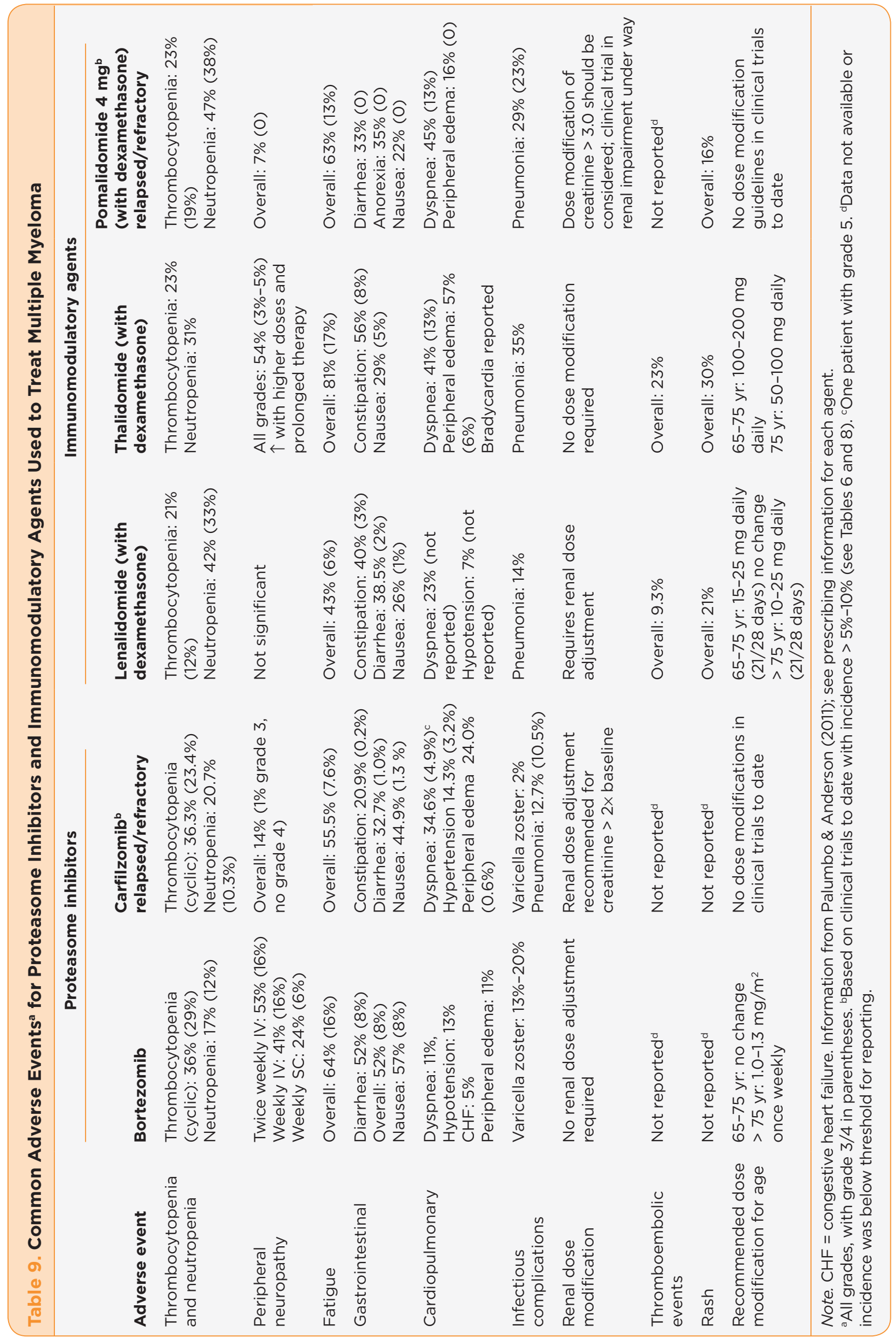




\section{Table 10. Clinical Management of Common Treatment-Emergent Adverse Events Associated With Proteasome Inhibitors and Immunomodulatory Agents Used in the Treatment of Multiple Myeloma}

\section{Adverse event \\ Asthenia/fatigue somnolence \\ Cardiopulmonary}

Constipation

Depression/anxiety

Diarrhea

Hypotension

Myelosuppression

Peripheral neuropathy

Rash

Renal clearance

Secondary

malignancies

Thromboembolic events

Varicella zoster

\section{Clinical management}

- Counsel patient regarding rest and activity, encourage strength training and endurance as tolerated; encourage adequate hydration

- Avoid concurrent meds causing asthenia or drowsiness; administer thalidomide at bedtime

- Baseline evaluation for cardiopulmonary risk: echocardiogram, pulmonary function testing, cardiovascular or pulmonary consultation as indicated

- Provide patient and caregiver with guidelines for reportable signs and symptoms, contact information

- Adequate hydration, modification of diet, use of laxatives and stool softeners

- May be exacerbated by steroids, fatigue, chronic disease

- Assessment for symptom distress with referral to support services as indicated

- Adequate hydration, assess fluid status and risk of fluid overload, monitor electrolytes; diet modification to avoid aggravating foods/beverages

- Antidiarrheal agents

- Dose modification rarely required

- Baseline evaluation of risk factors

- Increase noncaffeinated low-sugar oral fluids, additional IV hydration may reduce severity, balance with risk of fluid overload

- May require adjustment of antihypertensive medications

- Monitor $\mathrm{CBC}$, differential, platelet count every 1-2 wk for first $12 \mathrm{wk}$ and monthly thereafter or as clinically indicated

- Hold drug or reduce dose based on symptomatic cytopenias, bone marrow capacity to recover, combination therapy, and individual dosing guidelines

- Transfusions: PRBCs and platelets as indicated

- Growth factor administration: ESAs based on FDA-approved guidelines, G-CSF agents may be administered concurrently with IMiDs, should not be administered same day as proteasome inhibitors or chemotherapeutic agents

- Provide patient and caregiver with guidelines for reportable signs and symptoms, contact information

- Baseline assessment of patient, reassess at each visit

- Patient and caregiver education/early detection

- Dose adjustment or discontinuation of treatment as per prescribing information and clinical discretion

- Home safety evaluation, physical therapy, assistive devices as needed

- Symptom control with pharmacologic interventions, including pain management

- Generally self-limiting, treat symptomatically with antihistamines, topical agents

- Severe drug reactions (rare), stop offending medication for systemic symptoms

- Dose modification required for lenalidomide:

- Moderate (30 to $<60 \mathrm{~mL} / \mathrm{min}$ ): $10 \mathrm{mg}$ qd

- Severe (<30 mL/min, not requiring dialysis): $15 \mathrm{mg}$ q48h

- ESRD (<30 mL/min, requiring dialysis): $5 \mathrm{mg}$ qd following dialysis on following day

- Lenalidomide maintenance after HCT has been associated with a small number of secondary malignancies in patients treated with cyclophosphamide, etoposide, cisplatin; similar incidence to SEER data for patients $60-85 \mathrm{yr}$

- Evaluate risk factors

- Low-dose aspirin indicated for patients with $<2$ risk factors receiving IMiDs

- Anticoagulation recommended for $>2$ risk factors, monitor coagulation assays

- Prophylactic antiviral therapy is recommended for patients on continued treatment

- Careful monitoring for any early dermatomal pain, skin rash

Note. $\mathrm{CBC}=$ complete blood count; PRBCs = packed red blood cells; $\mathrm{ESA}=$ erythropoiesis-stimulating agent; FDA = US Food and Drug Administration; G-CSF = granulocyte colony-stimulating factor; IMiDs = immunomodulatory drugs;

ESRD = end-stage renal disease; $\mathrm{HCT}$ = hematopoietic cell transplant; SEER = Surveillance, Epidemiology and End Results. Information from NCCN (2013), Celgene (1998, 2005, 2013), Onyx Pharmaceuticals (2012), Millennium (2012). 
be familiar with the established guidelines for dose modification or in some cases selection of therapies for patients with MM and existing PN.

Thromboembolic events, including deep-vein thrombosis and pulmonary emboli, present an additional challenge in the treatment of MM. Multiple myeloma itself is a risk factor for thrombosis (Palumbo et al., 2008). Evaluation of each patient for additional risk factors for thrombosis is essential prior to thalidomide, lenalidomide, and pomalidomide therapy. All patients treated with these agents require thromboprophylaxis based on established guidelines.

The incidence of herpes zoster virus (HSV) reported with bortezomib is variable but was notably decreased when antiviral prophylaxis was mandated in the VISTA trial (Mateos et al., 2006). It is important to remember that antiviral medications require dose modification for renal impairment and should be dosed based upon creatinine clearance. Although there was no incidence of HSV reported in the PX-171-003-A1 trial with carfilzomib, antiviral prophylaxis was only required for patients with a history of herpes zoster or simplex.

Alteration in hemodynamics ranges from hypotension to hypertension, with both being reported in approximately $14 \%$ of patients receiving bortezomib, and hypertension alone reported for approximately 14\% with carfilzomib (Millennium, 2012; Onyx Pharmaceuticals, 2012). As the average age at diagnosis for MM is 69 years, cardiac comorbidities are common, and blood pressure management should incorporate a collaborative approach. Safety to avoid falls from orthostatic hypotension is a priority for patient education followed by modification of antihypertensive therapy.

\section{CONCLUSION}

The integration of novel agents into the treatment of MM has shifted the focus from an incurable disease to a disease that is chronic with a realistic hope of long-term survival and quality of life. Proteasome inhibitors and immunomodulatory agents are the backbone of novel therapies for the treatment of MM. Recent trials and next generation agents are particularly important for patients with relapsed or refractory disease, a fate faced by the majority of myeloma patients over the course of their disease. The improvement in overall survival reported with proteasome inhibitors and immunomodulatory agents illustrates the efficacy of these agents, the importance of early identification and management of treatment-related toxicities, and the significant contribution of clinical trials participation. Despite these exciting developments, MM patients continue to succumb to their disease and experience adverse events related to their disease and treatment. Continued patient enrollment in clinical trials including genomic analysis will be necessary to fully characterize and exploit targets within the malignant clone and the tumor microenvironment necessary to identify new agents to complement the existing novel therapies. The hope of someday finding a cure for this disease will require ongoing research.

Evolving strategies that include the combination of multiple agents to attack alternative pathways have improved clinical outcomes. These combinations offer significant promise to patients diagnosed with MM but also present a number of challenges. As treatment strategies are combined adverse events profiles will change. The numerous trials conducted throughout the world with variable trial design, patient populations, and clinical trial endpoints have produced a plethora of data that are difficult to consolidate into tangible clinical recommendations. Although algorithms for risk-adapted treatment of MM have been developed, a lack of consensus exists as to the optimal combination and sequencing of therapies, and the role and timing for autologous stem cell transplantation. We are fortunate to have so many good options for treatment of MM; however, this presents a challenge to patients and caregivers who may receive conflicting recommendations from various providers. Global working groups, such as the International Myeloma Foundation Working Group, have embarked on efforts to identify priorities for continued research initiatives and collaborative efforts to utilize existing data sources to maximize the benefit to patients and to future research.

The advanced practitioner in oncology plays an integral role in the early identification and clinical management of common adverse events; reporting of less common side effects that may not have been reported in clinical trials, and education of patients and caregivers about their disease, their individual treatment plan, and how they can take an active role in self-management of and reporting of adverse events. The application of advances in science together with effective clinical management and formation of a 
partnership with MM patients and their caregivers will provide the best opportunity for continued treatment and favorable clinical outcomes.

\section{DISCLOSURE}

Ms. Kurtin has acted as a consultant for Celgene, Millennium, and Onyx. Ms. Bilotti has acted as a consultant and served on speakers bureaus for Celgene, Millennium, and Onyx.

\section{REFERENCES}

Adams, J. (2004). The proteasome: A suitable antineoplastic target. Nature Reviews Cancer, 4, 349-360. http://dx.doi. org/10.1038/nrcl361

America Cancer Society. (2013). Cancer Facts \& Figures 2013. Atlanta, GA: American Cancer Society.

Attal, M., Lauwers-Cances, V., Marit, G., Caillot, D., Moreau, P., Facon, T.,...Harousseau, J. L. (2012). Lenalidomide maintenance after stem-cell transplantation for multiple myeloma. New England Journal of Medicine, 366, 1782-1791. http:// dx.doi.org/10.1056/NEJMoall14138

Celgene. (2013). Pomalyst (pomalidomide) package insert. Retrieved from http://www.pomalyst.com/docs/prescribinginformation.pdf

Celgene. (2005). Revlimid (lenalidomide) package insert. Retrieved from http://www.revlimid.com/pdf/MCL_PI.pdf

Celgene. (1998). Thalomid (thalidomide) package insert. Retrieved from http://www.thalomid.com/pdf/thalomid PI.pdf

Harvey, R., Lonial, S., Patel, P., McCulloch, L., Niesvizky, R., \& Kaufman, J. (2012). Carfilzomib dose and schedule need not be adjusted for baseline renal dysfunction, including patients on hemodialysis [Abstract 0844]. Presented at EHA 17 Amsterdam, 2012. Haematologica, 97(suppl 1).

Kloetzel, P. M. (2001). Antigen processing by the proteasome. Nature Reviews Molecular Cell Biology, 2(3), 179-188. http:// dx.doi.org/10.1038/35056572

Kumar, S., Bensinger, W., Reeder, C. B., Zimmerman, T. M., Berenson, J. R., Liu, G.,...Niesvizky, R. (2012a). Weekly dosing of the investigational oral proteasome inhibitor MLN9708 in patients (pts) with relapsed/refractory multiple myeloma (MM): A phase I study [Abstract 8034]. Journal of Clinical Oncology, 30(suppl).

Kumar, S. K., Lee, J. H., Lahuerta, J. J., Morgan, G., Richardson, P. G., Crowley, J.,...Durie, B. G. (2012b). Risk of progression and survival in multiple myeloma relapsing after therapy with IMiDs and bortezomib: A multicenter International Myeloma Working Group study. Leukemia, 26(1), 149-157. http:// dx.doi.org/10.1038/leu.2011.196

Kurtin, S. (2012). Myeloid toxicity of cancer treatment. Journal of the Advanced Practitioner in Oncology, 3, 209-224.

Lacy, M. Q., Allred, J. B., Gertz, M. A., Hayman, S. R., Short, K. D., Buadi, F.,...Mikhael, J. R. (2011). Pomalidomide plus lowdose dexamethasone in myeloma refractory to both bortezomib and lenalidomide: Comparison of 2 dosing strategies in dual-refractory disease. Blood, 118, 2970-2975. http:// dx.doi.org/10.1182/blood-2011-04-348896

Lacy, M. Q., Hayman, S. R., Gertz, M. A., Dispenzieri, A., Buadi, F., Kumar, S.,...Rajkumar, S. V. (2009). Pomalidomide (CC4047) plus low-dose dexamethasone as therapy for relapsed multiple myeloma. Journal of Clinical Oncology, 27, 5008-5014. http://dx.doi.org/10.1200/JCO.2009.23.6802

Lacy, M. Q., Hayman, S. R., Gertz, M. A., Short, K. D., Dis- penzieri, A., Kumar, S.,...Buadi, F. (2010). Pomalidomide (CC4047) plus low dose dexamethasone (Pom/dex) is active and well tolerated in lenalidomide refractory multiple myeloma (MM). Leukemia, 24(11), 1934-1939. http:// dx.doi.org/10.1038/leu.2010.190

Leleu, X., Attal, M., Arnulf, B., Moreau, P., Traulle, C., Michalet, M.,...Facon, T. (2011). High response rates to pomalidomide and dexamethasone in patients with refractory myeloma, final analysis of IFM 2009-02 [Abstract 812]. Blood (ASH Annual Meeting Abstract), 118.

Lenz, W. (1961). Thalidomide and congenital abnormalities. Lancet, 1, 45.

Lonial, S., Baz, R. C., Wang, M., Talpaz, M., Liu, G., \& Berg, D et al. (2012). Phase I study of twice-weekly dosing of the investigational oral proteasome inhibitor MLN9708 in patients (pts) with relapsed and/or refractory multiple myeloma (MM) [Abstract 8017]. Journal of Clinical Oncology, 30(15 suppl).

Ludwig, H., Durie, B. G., McCarthy, P., Palumbo, A., San Miguel, J. Barlogie, B.,...International Myeloma Working Group. (2012). IMWG consensus on maintenance therapy in multiple myeloma. Blood, 119(13), 3003-3015. http:// dx.doi.org/10.1182/blood-2011-11-37424

Martin, T., Vij, R., Badros, A., Patel, P., McCulloch, L., \& Jagannath, S. (2012). Carfilzomib is associated with a low rate of typically mild to moderate, non-dose limiting treatment emergent peripheral neuropathy [Abstract 0857]. Presented at EHA 17 Amsterdam, 2012 Haematologica, 97(suppl 1).

Mateos, M. V., Hernández, J. M., Hernández, M. T., Gutiérrez, N. C., Palomera, L., Fuertes, M.,...San Miguel, J. F. (2006). Bortezomib plus melphalan and prednisone in elderly untreated patients with multiple myeloma: Results of a multicenter phase 1/2 study. Blood, 108(7), 2165-2172. http:// dx.doi.org/10.1182/blood-2006-04-019778

McBride, W. G. (1961). Thalidomide and congenital abnormalities. Lancet, 2, 1358.

McCarthy, P. L., Owzar, K., Hofmeister, C. C., Hurd, D. D., Hassoun, H., Richardson, P. G.,...Linker, C. (2012). Lenalidomide after stem-cell transplantation for multiple myeloma. New England Journal of Medicine, 366, 1770-1781. http://dx.doi.org/10.1056/NEJMoal114083

Millennium. (2012). Velcade (bortezomib) package insert. Retrieved from http://www.velcade.com/files/PDFs/velcade_prescribing_information.pdf

Moreau, P. (2012). The future of therapy for relapsed/refractory multiple myeloma: Emerging agents and novel treatment strategies. Seminars in Hematology, 49, S33-S46. http://dx.doi.org/10.1053/j.seminhematol.2012.05.004

Moreau, P., Pylypenko, H., Grosicki, S., Karamanesht, I., Leleu, X., Grishunina, M.,...Harousseau, J. L. (2011). Subcutaneous versus intravenous administration of bortezomib in patients with relapsed multiple myeloma: A randomized, phase 3, non-inferiority study. Lancet, 12(5), 431-440. http://dx.doi.org/10.1016/S1470-2045(11)70081-X

Moreau,P., Richardson,P.G., Cavo, M., Orlowski, R.Z., San Miguel, J. F., Palumbo, A., \& Harousseau, J. L. (2012). Proteasome inhibitors in multiple myeloma: 10 years later. Blood, $120(5)$, 947-959. http://dx.doi.org/10.1182/blood-2012-04-403733

Morgan, G., Walker, B. A., \& Davies, F. E. (2012). The genetic architecture of multiple myeloma. Nature Reviews Cancer, 12, 335-348. http://dx.doi.org/10.1038/nrc3257

National Comprehensive Cancer Network. (2013). NCCN Clinical Practice Guidelines in Oncology. Multiple Myeloma, Version 2.2013. Retrieved from http://www.nccn.org/professionals/physician_gls/pdf/myeloma.pdf 
Niesvizky, R., Vij, R., Martin, T., Zonder, J., Wang, Z., \& Woo, T. (2011). Carfilzomib pharmacokinetics, safety, and activity in patients with relapsed or refractory multiple myeloma and renal dysfunction: Final results [Abstract 0890]. Presented at EHA 2011 London. Haematologica, 96 (suppl 2).

Nooka, A. K., Badros, A. Z., Patel, P., McCulloch, L., Lonial, S., \& Kaufman, J. L. (2012). Hematologic safety data from four phase II studies of single-agent carfilzomib in relapsed and/ or refractory multiple myeloma [Abstract 8086]. Journal of Clinical Oncology, 30 (15 suppl).

Onyx Pharmaceuticals. (2012). Kyprolis (carfilzomib) package insert. Retrieved from http://www.kyprolis.com/prescribing-information

Palumbo, A., \& Anderson, K. (2011). Multiple myeloma. New England Journal of Medicine, 364, 1046-1060. http://dx.doi. org/10.1056/NEJMra1011442

Palumbo, A., Bringhen, S., Liberati, A. M., Caravita, T., Falcone, A., Callea, V.,...Boccadoro, M. (2008). Oral melphalan, prednisone, and thalidomide in elderly patients with multiple myeloma: Updated results of a randomized controlled trial. Blood, 112(8), 3107-3114. http://dx.doi.org/10.1182/ blood-2008-04-149427

Palumbo, A., \& Cavallo, F. (2012) Have drug combinations supplanted stem cell transplantation in myeloma? Blood, 120, 4692-4698. http://dx.doi.org/ 10.1182/ blood-2012-05-423202

Palumbo, A., Hajek, R., Delforge, M., Kropff, M., Petrucci, M. T., Catalano, J.,...Dimopoulos, M. A. (2012). Continuous lenalidomide treatment for newly diagnosed multiple myeloma. New England Journal of Medicine, 366, 1759-1769. http:// dx.doi.org/10.1056/NEJMoal112704

Pan, B., \& Lentzsch, S. (2012). The application and biology of immunomodulatory drugs (IMiDs) in cancer. Pharmacology $\mathcal{E}$ Therapeutics, 136, 56-68. http://dx.doi.org/10.1016/j.pharmthera.2012.07.004

Quach, H., Kaiff, A., \& Spencer, A. (2012). Lenalidomide in multiple myeloma: Current status and future potential. American Journal of Hematology, 87, 1089-1095. http://dx.doi. org/10.1002/ajh.23234

Quach, H., Ritchie, D., Stewart, A. K., Neeson, P., Harrison, S., Smyth, M. J., \& Prince, H. M. (2010). Mechanism of action of immunomodulatory drugs (IMiDS) in multiple myeloma. Leukemia, 24, 22-32. http://dx/doi/org/10.1038/ leu.2009.236

Rajkumar, S. V. (2012). Doublets, triplets or quadruplets on novel agents in the treatment of newly diagnosed myeloma. $A S H$ Education Book, 2012(1), 354-361. http://dx.doi.org/10.1182/ asheducation-2012.1.354

Richardson, P. G., Barlogie, B., Berenson, J., Singhal, S., Jagannath, S., Irwin, D.,...Anderson, K. C. (2003). A phase 2 study of bortezomib in relapsed, refractory myeloma. New England Journal of Medicine, 348(26), 2609-2617. http://dx.doi. org/10.1056/NEJMoa030288

Richardson, P. G., Berdeja, J. G., Niesvizky, R., Lonial, S., Roy, V., Hari, P.,...Kumar, S. (2012). Oral weekly MLN9708, an investigational proteasome inhibitor, in combination with lenalidomide and dexamethasone in patients (pts) with previously untreated multiple myeloma (MM): A phase I/II study [Abstract 8033]. Journal of Clinical Oncology, 30(suppl).

Richardson, P. G., Sonneveld, P., Schuster, M., Irwin, D., Stadtmauer, E., Facon, T.,...Anderson, K. C. (2007). Extended follow-up of a phase 3 trial in relapsed multiple myeloma: Final time-to-event results of the APEX trial. Blood, 110(10), 35573560. http://dx.doi.org/10.1182/blood-2006-08-036947

Richardson, P. G., Spencer, A., Cannell, P., Harrison, S. J., Catley, L., Underhill, C.,...Anderson, K. C. (2011a). Phase 1 clinical evaluation of twice-weekly marizomib (NPI-0052), a novel proteasome inhibitor, in patients with relapsed/refractory multiple myeloma (MM) [Abstract 302]. Blood (ASH Annual Meeting Abstracts), 118.

Richardson, P., Siegel, D. S., Vij, R., Hofmeister, C. C., Jagannath, S., Chen, C.,...Anderson, K. C. (2011b). Randomized, open label phase $1 / 2$ study of pomalidomide (POM) alone or in combination with low-dose dexamethasone (LoDex) in patients (Pts) with relapsed and refractory multiple myeloma who have received prior treatment that includes lenalidomide (LEN) and bortezomib (BORT): Phase 2 results [Abstract 634]. Blood (ASH Annual Meeting Abstracts), 118.

San Miguel, J. F., Schlag, R., Khuageva, N. K., Dimopoulos, M. A., Shpilberg, O., Kropff, M.,...Richardson, P. G. (2008). Bortezomib plus melphalan and prednisone for initial treatment of multiple myeloma. New England Journal of Medicine, 359, 906-917. http://dx.doi.org/10.1056/NEJMoa0801479

San Miguel, J. F., Schlag, R., Khuageva, N. K., Dimopoulos, M. A., Shpilberg, O., \& Kropff, M.,...Richardson, P. G. (2012). Continued overall survival benefit after 5 years' follow-up with bortezomib-melphalan-prednisone (VMP) versus melphalan-prednisone (MP) in patients with previously untreated multiple myeloma, and no increased risk of second primary malignancies: Final results of the phase 3 VISTA trial [Abstract 476]. Blood (ASH Annual Meeting Abstracts), 118.

San Miguel, J. F., Schlag, R., Khuageva, N. K., Dimopoulos, M.A., Shpilberg, O., Kropff, M.,...Richardson, P. G. (2013). Persistent overall survival benefit and no increased risk of second malignancies with bortezomib-melphalan-prednisone versus melphalan-prednisone in patients with previously untreated multiple myeloma. Journal of Clinical Oncology, 31, 448-455. http://dx.doi.org/10.1200/JCO.2012.41.6180

Schey, S. A., Fields, P., Bartlett, J. B., Clarke, I. A., Ashan, G., Knight, R. D.,...Dagleish, A. G. (2004). Phase I study of an immunomodulatory thalidomide analog, CC-4047, in relapsed or refractory multiple myeloma. Journal of Clinical Oncology, 22(16), 3269-3276. http://dx.doi.org/10.1200/ JCO.2004.10.052

Sedlarikova, L., Kubiczkova, L., Sevcikova, S., \& Hajek, R. (2012). Mechanism of immunomodulatory drugs in multiple myeloma. Leukemia Research, 36, 1218-1224. http://dx.doi. org/10.1016/j.leukres.2012.05.010

Siegel, D. S., Martin, T., Wang, M., Vij, R., Jakubowiak, A. J., Lonial, S.,...Jagannath, S. (2012). A phase 2 study of singleagent carfilzomib (PX-171-003-A1) in patients with relapsed and refractory multiple myeloma. Blood, 120, 2817-2825. http://dx.doi.org/10.1182/blood-2012-05-425934

Singhal, S., Mehta, J., Desikan, R., Ayers, D., Roberson, P., Eddlemon, P.,...Barlogie, B. (1999). Antitumor activity of thalidomide in refractory multiple myeloma. New England Journal of Medicine, 341, 1565-1571. http://dx.doi.org/10.1056/ NEJM199911183412102

Stadtmauer, E. A. (2010). Tailoring initial treatment for newly diagnosed, transplantation-eligible multiple myeloma. Oncology (Williston Park), 24(suppl 2), 7-13.

Stewart, K. (2012). Novel therapeutics in multiple myeloma. Hematology, 17(suppl 1), S105-S108. http://dx.doi.org/10.1179/ $102453312 X 13336169156131$ 